\title{
Osteochondrosis dissecans in glenoid cavity of Korean War casualty's scapula
}

\author{
Hyejin Lee ${ }^{1,2}$, Kyungmin Koh ${ }^{1}$, Minho Cha ${ }^{1}$, Tan Namkoong ${ }^{1}$, Sang Joon Park ${ }^{3,4}$, Doo Hee Lee ${ }^{5}$ \\ Ji Eun $\mathrm{Kim}^{6}$, Dong Hoon Shin ${ }^{2,6}$ \\ ${ }^{1}$ Ministry of National Defense Agency for KIA Recovery \& Identification, Seoul, ${ }^{2}$ Institute of Forensic and Anthropological Science, Seoul National \\ University College of Medicine, Seoul, ${ }^{3}$ Department of Radiology, Seoul National University College of Medicine, Seoul, ${ }^{4}$ Department of Radiology, \\ Seoul National University Hospital, Seoul, ${ }^{5}$ Department of Research and Development, MEDICALIP Co. Ltd., Seoul, ${ }^{6}$ Laboratory of Bioanthropology, \\ Paleopathology and History of Diseases, Department of Anatomy, Seoul National University College of Medicine, Seoul, Korea
}

\begin{abstract}
Since the first description of this disease in 1887, there are rare reports on osteochondrosis dissecans (OCD) found in the glenoid cavity by way of anthropological studies. During an excavation project for recovery of the remains of Korean War casualties, a skeletonized soldier was found inside a cave fort at the Arrowhead Ridge of the demilitarized zone (DMZ), South Korea. In our recovery and examination of a Korean War casualty in DMZ, we identified a possible OCD in the individual's glenoid cavity of a right-sided scapula by radiological analysis and computed tomography reconstruction. This is a rare case of scapular OCD discovered in an archaeologically investigated skeleton.
\end{abstract}

Key words: Archaeology, Anthropology, Osteochondritis dissecans, Radiology

Received March 30, 2021; Revised May 2, 2021; Accepted May 14, 2021

\section{Introduction}

Osteochondritis (or osteochondrosis) dissecans (OCD) is an acquired or idiopathic inflammatory joint disease that causes focal changes in articular cartilage. The etiology of OCD is likely related to strenuous activity, trauma, genetic factors, avascular necrosis, endochondral ossification abnormality, or fat emboli. It induces a detachment or separation of subchondral bone or cartilaginous segments from the underlying bones [1]. It finally leaves either a stable or

\section{Corresponding author:}

Hyejin Lee (iD

Ministry of National Defense Agency for KIA Recovery \& Identification, Seoul 06984, Korea

E-mail:chloe110720@gmail.com

Dong Hoon Shin (iD

Institute of Forensic and Anthropological Science, Seoul National University College of Medicine, Seoul 03080, Korea

E-mail: cuteminjae@gmail.com somewhat unstable bony fragment inside the knee, ankle, or elbow joint [2].

OCD has been reported in archaeological skeletons [3]. During the research on the Late Holocene skeletons from Southern Patagonia, OCD cases possibly due to strenuous physical activity were found (Zúñiga Thayer et al., 2020) [4]. In Anderson's research [5] on medieval-to-post-medieval skeletons rescued from San Pietro Barisano Church, the child case exhibited a circular defect in the cuboid bone, a possible sign of OCD. The same author also had reported OCD cases from medieval skeletons excavated at Norwich, England [6]. When Vikatou et al. [7] examined 19th century skeletons from Middenbeemster (the Netherlands), they found that pedal OCD prevalence was distinctly high among the cases, probably due to repetitive trauma incurred by the hard physical labor entailed in raising livestock. Pany-Kucera et al. [8] reported an OCD case in subadult skeletons from the Iron Age Hallstatt graveyard.

Nevertheless, reports of OCD from archaeologically investigated skeletons remain rare. This is understandable, as OCD prevalence in human populations generally is very low 
$(<1 \%)$. Especially in East Asia, there have been no anthropological reports of OCD found in any archaeologically obtained human bones. Recently, we examined over 300 Korean war casualties' skeletons found in the demilitarized zone (DMZ). During our forensic examination of the skeletons, we found an anthropologically significant case manifesting possible signs of OCD in the glenoid cavity of the scapula.

\section{Case Report}

In 2018, an excavation project for recovery of the remains of war casualties was initiated in the region of the DMZ. The Battle of Arrowhead Ridge (1952-1953), an engagement of the Korean War, resulted in approximately 4,000 soldiers killed or missing in action. The excavation site is a cave fort at the top of Arrowhead Ridge (Fig. 1). A skeletonized soldier (Case no. 20-DMZ-28) was found inside a cave fort lying in prone position (face down) (Fig. 2). He wore combat boots on both feet; a belt and buckle were found in the pelvic area. Hand grenades (MK2) were discovered beside both of his arms. The individual's skeletal remains were moved to the headquarters of the Ministry of National Defense Agency for KIA Recovery \& Identification (MAKRI, Seoul, Korea).

To estimate a biological profile of the soldier, we followed the standard bioanthropological procedures of Buikstra et al. [9]. Age was estimated by degenerative changes in osteology and dental attrition [10]. In brief, the skeleton was determined to be that of a male by the shape of the pelvic bone. His ancestry was presumed to be an Asian based on the morphologies of the nose, nasal aperture, and projecting zygomatic process of the facial bones. As for the age estimation,

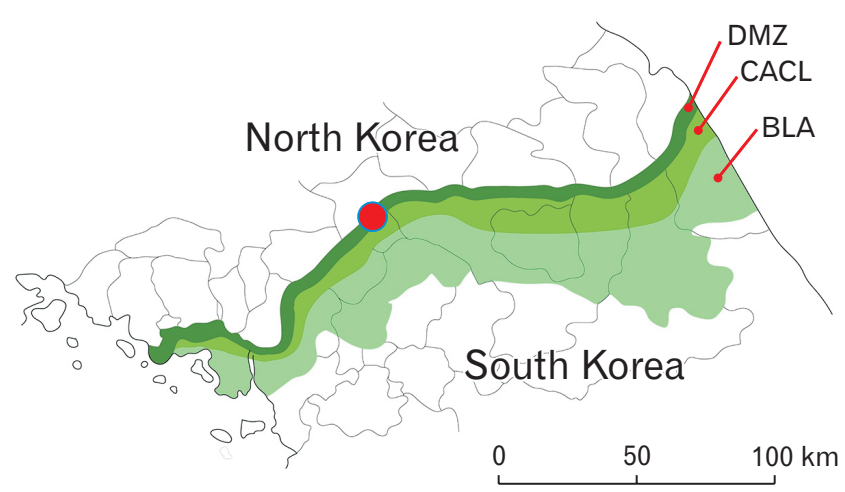

Fig. 1. The location of battlefield (red circle) at the Arrowhead Ridge of Korean War. BLA: border line area, CACL: civilian access control line, DMZ: demilitarized area. we note that most of the long-bone epiphyses were completely fused, but no degenerative changes were observed in the joints. The degree of dental attrition was B1-B2 by Lovejoy et al.'s method [10]. Age estimation by teeth indicated that the individual had been between 16 and 20 years old. We used the estimation formula for an East Asian male's stature introduced by Trotter and Gleser [11]. His height was estimated to have been approximately $167.2 \mathrm{~cm}$. We examined the teeth for carious and other pathological lesions with a magnifying glass. Caries was observed in a tooth (right upper first molar), forming small cavities around the occlusal surface. Calculus was deposited in the posterior teeth (premolars and molars).

Anthropological examination was also performed for the right-sided scapula of the individual. In the scapula of the soldier, we found a possible sign of OCD (Fig. 3). In brief, an intra-articular bony fragment was found at the center of the glenoid cavity; and around it, the bony defect, possibly an infarcted area, could be identified as well. On the glenoid cavity surface, the concentric bony fragment appeared to be separated from the underlying bone; but a part of it was still attached to the bone, given its stable fixation on the scapula. Around the bony fragment, there was a concave defect with steep-sided edges as described in a previous report of OCD [12]. The lesion appeared to represent phase IIb among the OCD stages proposed by Bohndorf [13]. That is, the bony fragment was mostly demarcated by the defect around it; but the separation of the osseous part from its bed was not complete. In case of left-sided scapula, however, we could not find similar signs of OCD on the glenoid cavity surface.

To see the separation pattern of the bony fragment more

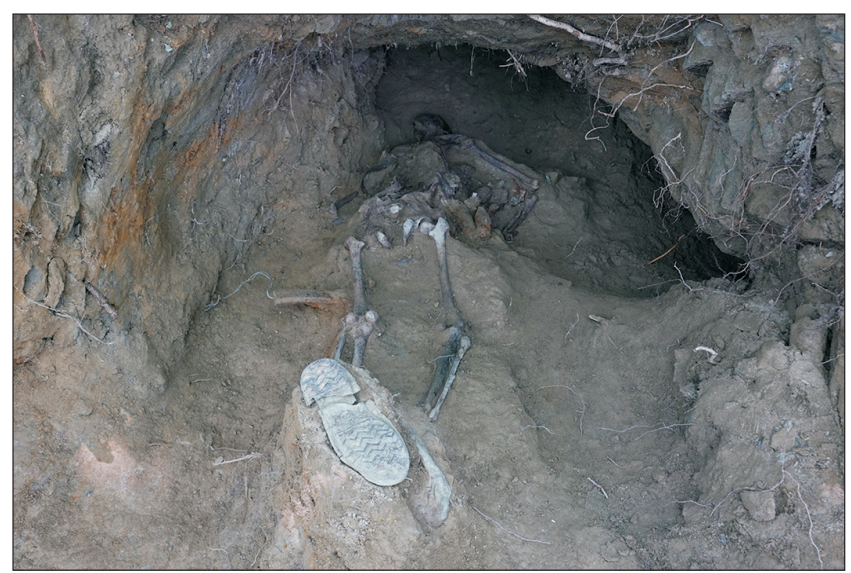

Fig. 2. Skeletons of a soldier discovered inside the cave fort (Case no. 20-DMZ-28). 

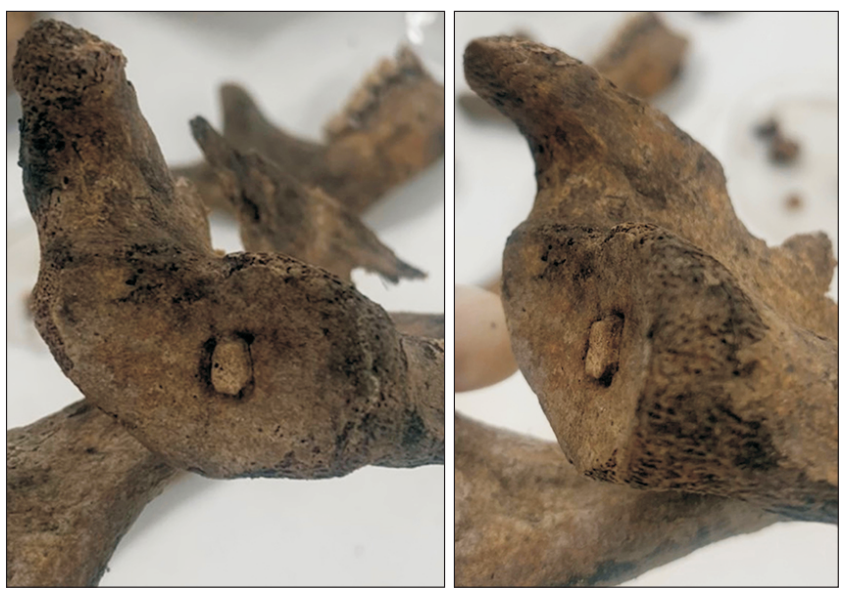

Fig. 3. A soldier's scapula. Note possible signs of osteochondrosis dissecans in glenoid cavity: intra-articular bony fragment and the bony defect around it with steep-sided edge. The concentric bony fragment is separated from underlying bone; but part of it still seems to be attached to the bone.
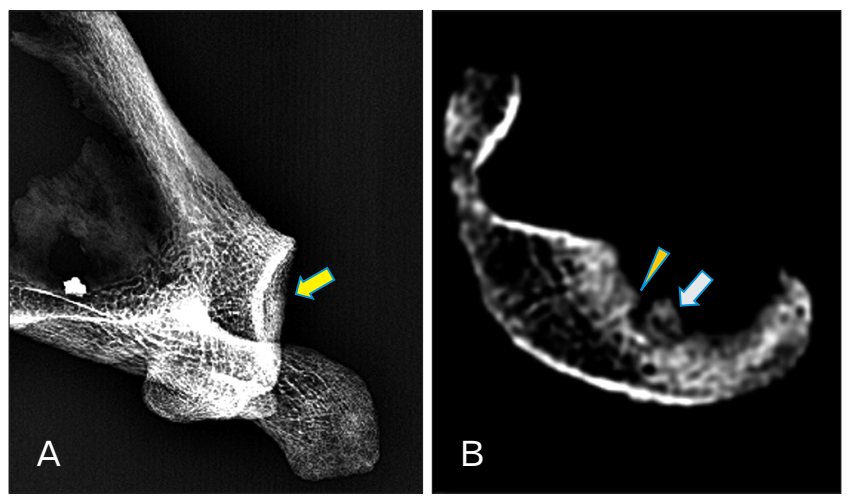

Fig. 4. Radiological images for osteochondrosis dissecans like lesion. (A) Plain X-ray radiography. Separation of fragment and radiolucency around it are not clearly observed. (B) Cross-section computed tomography image. Note bony fragment (arrows) and a concave defect with steep-sided edge around it (arrowhead).

clearly, we used radiological tools. A plain X-ray on the scapula was taken at MAKRI headquarters. On the plain Xray radiography, the concentric bony fragment could be seen; however, its separation (the presumed radiolucency around it) was not clearly identifiable (Fig. 4A). We thus performed the computed tomography (CT) analysis on the soldier's scapula. A CT scan was conducted at the National Forensic Service Seoul Institute (Seoul, Korea). The CT radiological data were obtained by a 128 -slice multidetector CT (MDCT) scanner (175 mA, 120 kV, $0.6 \mathrm{~mm}$ slice thickness; SOMATOM Definition AS+, Siemens, Munich, Germany). For 3-dimensional (3D) reconstruction, stand-alone medical
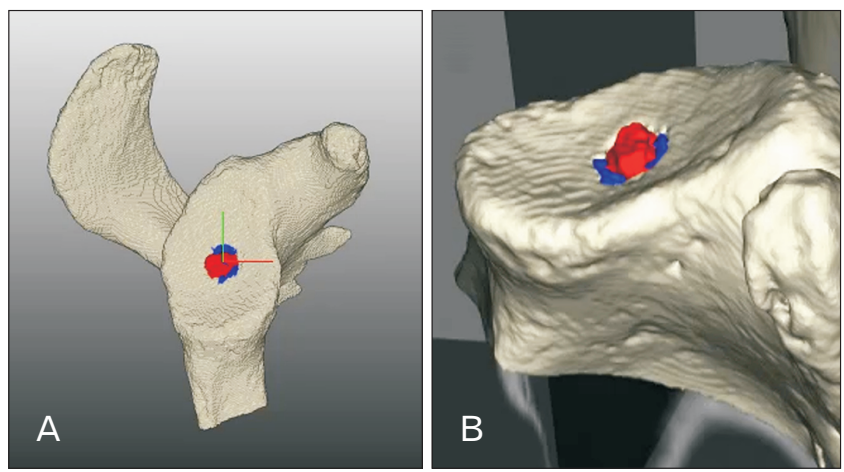

Fig. 5. Three-dimensional reconstruction of a scapula computed tomography images. Reconstructed image of a scapula with marks for bony fragment (red-colored) and defect around it (blue-colored). Three-dimensional reconstructed scapula viewed from above (A) and obliquely (B).

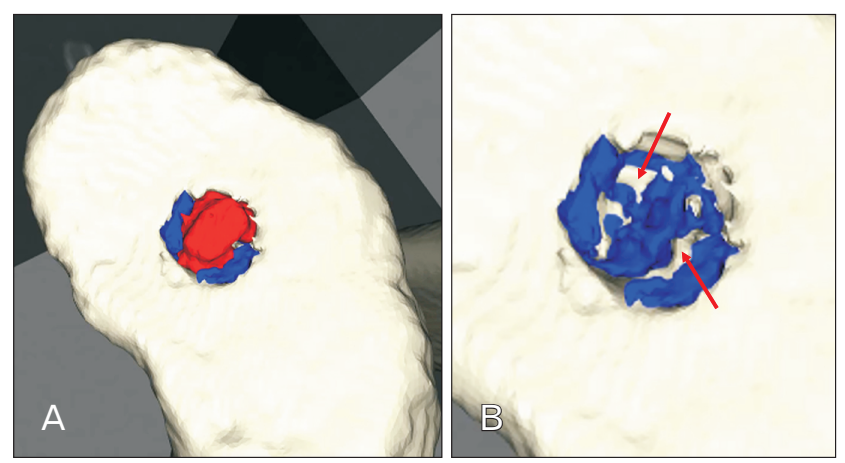

Fig. 6. Three-dimensional reconstructed computed tomography images of bony fragment (red-colored) and defect around it (bluecolored). The reconstructed images with bony fragment positioned (A) and removed (B). In (B), note white-colored parts (arrows) indicating bony connections between separated fragment and underlying bone.

3D segmentation \& modeling software (MEDIP Pro v2.1.3; MEDICALIP, Seoul, Korea) was used. In the cross-section CT image, we found the bony fragment in the scapula along with a concave defect with steep-sided edges (Fig. 4B). In the 3D-reconstruction of the CT images (Fig. 5A), the bony fragment and concave defect were clearly evident (Fig. 5B). The concave defect separated the bony fragment from the surrounding scapula. Nonetheless, the separation was not perfect, as a part of the bony fragment remained attached to the surrounding bone (Fig. 6). Fig. 7 exhibits the incomplete separation of the bony fragments from the concave defect around it. Judging from these radiological findings, we confirmed that this was likely a case of phase IIb of OCD [13]. 


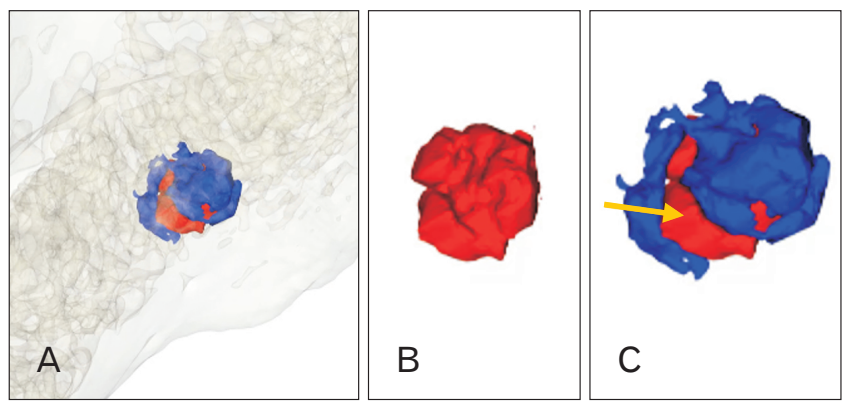

Fig. 7. (A) Bony fragment (red-colored) and defect around it (bluecolored). Three-dimensional reconstructed computed tomography images embedded in scapula. (B) Bony fragment. (C) Arrow indicates the passage through which the connection part between bony fragment and underlying bone is present.

\section{Discussion}

Among several diseases similar to OCD, old osteochondral fracture is likely the most difficult to distinguish from it [12]. In general, OCD is known as an acquired lesion in the subchondral bone, characterized by osseous collapse, resorption, and the formation of sequestrum with the involvement of the cartilage that is unrelated to fractures in osteochondral parts [2]. To confirm whether a case is OCD, clinicians usually try to find clinical signs such as chondral separation, chondral flaps, or hemarthrosis. However, these signs are not useful for diagnosis of OCD in human bones obtained from archaeological sites. Differential diagnosis of OCD lesions in archaeological skeletons is certainly not easy.

In this context, anatomical and radiological examinations must proceed cautiously so as to successfully confirm OCD in anthropological cases. For example, OCD must be carefully differentiated from osteochondral fracture fragment, which is characterized as a flat surface related to a tangential injury. OCD, meanwhile, has a defect with characteristic steep-sided edges around the bony fragment, which was also evidenced in the present case by our anatomical as well as radiological examinations. Moreover, the soldier, as noted earlier, was likely to have been an adolescent or young male aged 16-20 years, which finding also is consistent with a known characteristic of OCD [12]. Taking all of evidence together, we could conclude that our skeleton is a case of OCD occurring in the glenoid fossa of a Korean War casualty's scapula.

This report is significant to anatomists, considering that there have been only a few articles reported OCD involving any human bones unearthed at excavation sites [4-8]. Our case is unique also in that osteochondral lesion rarely in- volves the shoulder [3]. This is the first report on OCD in the shoulder joint of an archaeological skeleton.

According to Andriolo et al. [14], OCD's etiology is largely attributed to two causal factors: biological and mechanical. With respect to the second, our young soldier was confirmed to have died in the course of a major battle of the Korean War, and as such, was very likely to have been subject to intense physical exertion, and even trauma, at that time. Actually, OCD was not rarely reported in modern arthroscopic surgery on military troops during Operation Desert Shield (Buckley et al., 1992) [15]. These, exertion and trauma, can thus be considered to be the most likely mechanical OCDinducing factors in our particular case. Nevertheless, we also note that the etiology of OCD includes genetic factors, avascular necrosis, endochondral ossification abnormality, or fat emboli [1]. These factors cannot be entirely ruled out from the possible causes of OCD found in the soldier's scapula even if that possibility is likely low compared to exertion and trauma.

\section{ORCID}

Hyejin Lee: https://orcid.org/0000-0002-2876-8391

Kyungmin Koh: https://orcid.org/0000-0002-6564-8241

Minho Cha: https://orcid.org/0000-0003-2078-5506

Tan Namkoong: https://orcid.org/0000-0002-3369-2774

Sang Joon Park: https://orcid.org/0000-0003-1013-681X

Doo Hee Lee: https://orcid.org/0000-0002-5838-6925

Ji Eun Kim: https://orcid.org/0000-0002-0799-1084

Dong Hoon Shin: https://orcid.org/0000-0001-8032-1266

\section{Author Contributions}

Conceptualization: HL, DHS. Anthropological data analysis: HL, KK, MC, TN, JEK, DHS. Radiological data analysis: SJP, DHL. Drafting and revision of the manuscript: HL, DHS. Approval of the final version of the manuscript: all authors.

\section{Conflicts of Interest}

No potential conflict of interest relevant to this article was reported. 


\section{Acknowledgements}

This work was supported by the Ministry of Science and ICT of the Republic of Korea and the National Research Foundation of Korea (NRF-2019S1A5C2A01083578). The authors express sincere condolences to the families and/ or descendants of soldiers killed or missing in action at Arrowhead Ridge during the Korean War. We specially thank Drs. Won-Joon Lee, Se-Min Oh, and Ji-Hwan Park of the National Forensic Service Seoul Institute for their generous help during CT scanning.

\section{References}

1. Clanton TO, DeLee JC. Osteochondritis dissecans. History, pathophysiology and current treatment concepts. Clin Orthop Relat Res 1982;(167):50-64.

2. Edmonds EW, Polousky J. A review of knowledge in osteochondritis dissecans: 123 years of minimal evolution from König to the ROCK study group. Clin Orthop Relat Res 2013;471:111826.

3. Chu PJ, Shih JT, Hou YT, Hung ST, Chen JK, Lee HM. Osteochondritis dissecans of the glenoid: a rare injury secondary to repetitive microtrauma. J Trauma 2009;67:E62-4.

4. Zúñiga Thayer R, Suby J, Luna L, Flensborg G. Osteochondritis dissecans and physical activity in skeletal remains of ancient hunter-gatherers from Southern Patagonia. Int J Osteoarchaeol 2021;31:77-87.

5. Anderson T. A medieval Italian child with osteochondritis dissecans of the cuboid. Foot 2000;10:216-8.
6. Anderson T. An example of unhealed osteochondritis dissecans of the medial cuneiform. Foot 2001;11:251-3.

7. Vikatou I, Hoogland MLP, Waters-Rist AL. Osteochondritis Dissecans of skeletal elements of the foot in a 19th century rural farming community from The Netherlands. Int J Paleopathol 2017;19:53-63.

8. Pany-Kucera D, Kern A, Reschreiter H. Children in the mines? Tracing potential childhood labour in salt mines from the Early Iron Age in Hallstatt, Austria. Child Past 2019;12:67-80.

9. Buikstra JE, Ubelaker DH. Standards for data collection from human skeletal remains: proceedings of a Seminar at The Field Museum of Natural History. 12154th ed. Fayetteville: Arkansas Archeological Survey; 1994.

10. Lovejoy CO, Meindl RS, Mensforth RP, Barton TJ. Multifactorial determination of skeletal age at death: a method and blind tests of its accuracy. Am J Phys Anthropol 1985;68:1-14.

11. Trotter M, Gleser GC. A re-evaluation of estimation of stature based on measurements of stature taken during life and of long bones after death. Am J Phys Anthropol 1958;16:79-123.

12. Bradley J, Dandy DJ. Osteochondritis dissecans and other lesions of the femoral condyles. J Bone Joint Surg Br 1989;71:51822.

13. Bohndorf K. Osteochondritis (osteochondrosis) dissecans: a review and new MRI classification. Eur Radiol 1998;8:103-12.

14. Andriolo L, Crawford DC, Reale D, Zaffagnini S, Candrian C, Cavicchioli A, Filardo G. Osteochondritis dissecans of the knee: etiology and pathogenetic mechanisms. a systematic review. Cartilage 2020;11:273-90.

15. Buckley SL, Alexander A, Jones M, Culp RW, Smallman T. Arthroscopic surgery of the knee: its role in the support of U.S. troops during Operation Desert Shield on USNS mercy. Arthroscopy 1992;8:359-62. 